Laura Summer and Jack Hoadley Health Policy Institute, Georgetown University 
The Commonwealth Fund, among the first private foundations started by a woman philanthropist-Anna M. Harkness-was established in 1918 with the broad charge to enhance the common good.

The mission of The Commonwealth Fund is to promote a high performing health care system that achieves better access, improved quality, and greater efficiency, particularly for society's most vulnerable, including low-income people, the uninsured, minority Americans, young children, and elderly adults.

The Fund carries out this mandate by supporting independent research on health care issues and making grants to improve health care practice and policy. An international program in health policy is designed to stimulate innovative policies and practices in the United States and other industrialized countries. 


\title{
THE ROLE OF MEDICAID MANAGED CARE IN HEALTH DELIVERY SYSTEM INNOVATION
}

\author{
Laura Summer and Jack Hoadley \\ Health Policy Institute, Georgetown University
}

APRIL 2014

Abstract: States are increasingly turning to Medicaid managed care as a key strategy to manage costs and encourage innovation in health care delivery. This report examines health care providers' perspectives on the role of managed care in improving health services for low-income adults in four communities: Milwaukee, Wisconsin; Oakland, California; Seattle, Washington; and Washington, D.C. It finds that providers do not generally perceive Medicaid managed care as a catalyst for delivery system reform. Fragmented delivery systems, limits on the types of services for which managed care organizations are at risk, and the volatility in managed care markets all present challenges to improving care delivery. Policy and operational changes could enhance the role of Medicaid managed care in promoting patient-centered, coordinated, and high-quality care.

Support for this research was provided by The Commonwealth Fund. The views presented here are those of the authors and not necessarily those of The Commonwealth Fund or its directors, officers, or staff. To learn more about new publications when they become available, visit the Fund's website and register to receive email alerts. Commonwealth Fund pub. 1741. 



\section{CONTENTS AND LIST OF EXHIBITS}

$\begin{array}{lr}\text { ABOUT THE AUTHORS } & 6\end{array}$

$\begin{array}{ll}\text { ACKNOWLEDGMENTS } & 6\end{array}$

$\begin{array}{lr}\text { EXECUTIVE SUMMARY } & 7\end{array}$

$\begin{array}{lr}\text { INTRODUCTION } & 9\end{array}$

$\begin{array}{lr}\text { ABOUT THIS STUDY } & 9\end{array}$

ACTIVITIES TO IMPROVE SERVICE DELIVERY

Care Management 11

Promoting More Appropriate Use of Emergency Departments 12

Facilitating Transitions from the Hospital to the Community 12

Using Plan Data to Improve Service Delivery $\quad 12$

Integrating Physical and Behavioral Health Services

$\begin{array}{ll}\text { Fostering Communication Among Providers } & 13\end{array}$

CHALLENGES ASSOCIATED WITH MANAGED CARE 13

Volatility in the Managed Care Market $\quad 14$

Disruptions in the Delivery of Care Related to Volatility 14

$\begin{array}{ll}\text { Diversion of Provider Resources } & 14\end{array}$

Confusion Among Beneficiaries $\quad 15$

$\begin{array}{ll}\text { POLICY RECOMMENDATIONS } & 15\end{array}$

$\begin{array}{ll}\text { DISCUSSION } & 16\end{array}$

$\begin{array}{ll}\text { APPENDIX 1. METHODOLOGY } & 17\end{array}$

APPENDIX 2. MANAGED CARE ORGANIZATIONS IN THE FOUR COMMUNITIES 19

$\begin{array}{lr}\text { APPENDIX 3. DISCUSSION GUIDE } & 20\end{array}$

EXHIBIT $1 \quad$ CHARACTERISTICS OF STUDY COMMUNITIES

EXHIBIT 2 INTERVIEW RESPONDENTS

EXHIBIT $3 \quad$ PARTICIPATING ORGANIZATIONS 


\section{ABOUT THE AUTHORS}

Laura Summer, M.P.H., a senior research scholar at Georgetown University's Health Policy Institute, has more than 20 years of experience in federal and state government, independent policy organizations, and academic institutions. Summer directs research that examines the manner in which states design, administer, and operate publicly financed health and long-term care programs. She also studies the impact of various aspects of the Medicare program on beneficiaries' access to and use of services, and has written extensively on methods to increase enrollment in public programs for moderate- and low-income Americans of all ages. Summer has a master of public health degree from the University of Michigan.

Jack Hoadley, Ph.D., is a research professor in the Health Policy Institute at Georgetown University, where he leads research projects on Medicare, Medicaid, and other health financing topics, with a particular focus on issues related to prescription drugs. In recent projects, Hoadley has studied various aspects of the Medicare Part D drug benefit, including spending trends, factors influencing decisions to switch plans, the impact of plan benefit design features on generic drug use, the use of formularies, the impact of the coverage gap, and policy options for simplifying and standardizing the program. Other recent work has included projects on Medicaid changes in Florida and Connecticut. He was recently appointed to a three-year term as a member of the Medicare Payment Advisory Commission. Hoadley received his M.A. and Ph.D. in political science from the University of North Carolina at Chapel Hill.

\section{ACKNOWLEDGMENTS}

The authors thank all of the respondents in the four communities for taking time out of their busy schedules to meet with us and for their good work on behalf of the Medicaid beneficiaries in their communities. We also are grateful to Rebecca Wener for her many valuable contributions as the research assistant throughout this project.

Editorial support was provided by Martha Hostetter. 


\section{EXECUTIVE SUMMARY}

State policymakers are increasingly looking to Medicaid managed care as a key strategy to manage costs and encourage innovation in health care delivery. This study was designed to assess health care providers' perceptions of the impact of Medicaid managed care on service delivery. The findings are based on interviews in early 2013 with providers and care coordinators serving Medicaid populations in four communities. We also interviewed staff from county health departments, health plans, and other organizations to understand local delivery systems and improvement initiatives. Each of the communities studied-Milwaukee, Wisconsin; Oakland, California; Seattle, Washington; and Washington, D.C.- - has robust coverage for a significant share of low-income adults through Medicaid or other state-funded coverage, and each uses comprehensive risk-based managed care for that population. Despite differences in local circumstances and state Medicaid programs, common themes emerged in conversations across the four communities.

For the most part, providers in the four communities regard health plans more as administrative entities than as innovators in delivery system reform. They do not perceive managed care organizations (MCOs) to be the primary sponsors of efforts to improve health care delivery for Medicaid beneficiaries, but report that some are involved to a certain extent. Other community stakeholders have undertaken initiatives to improve care delivery, including activities to reduce use of hospital emergency departments (EDs), provide optimal care for patients after inpatient stays, coordinate physical and behavioral health services, and improve communication among providers. Grants or other special funding streams available for a limited time usually finance these activities. Respondents also note that community-based MCOs associated with safety-net providers tend to be more involved than other health plans in delivery system improvements.

Providers observed that managed care systems are designed to improve quality and control costs by encouraging competition among MCOs, but this may limit the extent to which competing plans participate in collaborative improvement efforts. Further, providers felt that plans that do not have strong local ties may not be as involved or as effective in community collaborations. Also, many respondents said that when MCOs are not at risk for the full continuum of care-for example, when they cover physical but not mental health services-they may have limited ability to promote integration and coordination of care.

In three of the four communities studied, managed care plans joined and left the Medicaid program just prior to or at the time of, the site visits. This led to volatility that interrupted established patient-provider relationships, changed policies and procedures, and disrupted community-based efforts to improve service delivery. Providers noted that in shifting markets, beneficiaries often are assigned to new plans without regard for their longstanding care relationships or their cultural or linguistic needs or preferences. These events may disrupt care arrangements and, in the worst cases, produce adverse consequences for beneficiaries' health. Providers spoke about diverting resources to counsel patients about their new coverage or assist them in changing plans.

Many providers noted that fragmented health care systems in their communities do not support their efforts to improve access or deliver patient-centered care. As one said, "Our funding streams and information systems are throttling us in our attempt to do something different." Based on providers' perceptions, efforts on the part of MCOs to expand or enhance certain practices could be helpful in promoting the effective and efficient delivery of coordinated care.

- MCOs could contract with local trusted organizations or develop their own care management programs. Respondents emphasized that care managers making frequent, in-person contact with patients would be more effective than efforts to manage or coordinate care by telephone.

- Primary care providers say that plans could encourage appropriate use of EDs or better posthospital transitions by providing encounter data about hospital visits to them on a timely basis. 
- Primary care providers and referral specialists say they need accurate and current lists of network specialists who will accept referrals.

- MCOs could consider ways to reimburse services such as group or home visits, which safety-net providers cited as being particularly helpful for patients with complex conditions.

- Reimbursement for more types of nonphysician professionals, such as patient navigators, and payment for appropriate supportive services, such as child care, transportation, or interpreters for medical appointments, could promote patientcentered care.

Certain policy or operational changes on the part of states could promote patient-centered care in Medicaid managed care programs and improve population health.

- To minimize market volatility, states could require that MCOs make long-term commitments to the program, discourage plan withdrawals by excluding reentry for a period of time, and minimize rounds of competition for new contracts.

- To minimize disruption in care associated with market volatility, states could consider current provider relationships in making plan assignments and require that new plans honor prior authorizations and provider relationships for ongoing care.
- To promote collaborative community efforts, states could develop new performance measures or payfor-performance programs that credit MCOs for working with other community stakeholders to achieve improvements in service delivery for Medicaid beneficiaries.

- To encourage plans to compete on the basis of quality and to help enrollees and providers differentiate among plans, states could make easily understood, comparative information about MCOs publicly available on a timely basis.

The use of managed care is not the only approach to achieving high performance in the delivery of Medicaid services. Yet, activity and interest in Medicaid managed care are high and likely to increase with the expansion of Medicaid to cover more low-income adults in many states under the Affordable Care Act. Therefore, certain policy and operational changes, as well as ongoing program monitoring and evaluation, are recommended to promote patient-centered, coordinated care. 


\section{INTRODUCTION}

A key strategy for achieving high performance in health care organizations is to organize care provision around the needs of the patient and ensure that services are accessible and well coordinated. ${ }^{1}$ These goals are particularly important for Medicaid beneficiaries, who tend to be less healthy and to require more-complex care than other individuals. As an example, one-third of poor adults with Medicaid coverage report being in fair or poor general health, and about one-fifth report having fair or poor mental health-higher proportions than found among other poor adults. ${ }^{2}$ But ensuring that beneficiaries have sufficient access to care can be problematic, particularly because many health care providers do not accept Medicaid insurance. ${ }^{3}$

In an effort to control costs and encourage innovation in health care delivery, state policymakers are increasingly looking to Medicaid managed care. Currently, more than half of states use or are contemplating use of "risk-based" managed care to deliver Medicaid services for adults. ${ }^{4}$ Some state policymakers see in managed care organizations (MCOs) — which receive payments to provide a set of services for an enrolled population - the potential to control costs or at least achieve more predictable spending. Others point to their potential to encourage innovations in health care delivery or increase access to care, particularly for Medicaid beneficiaries with complex conditions. A further advantage often cited is the greater flexibility MCOs have compared with traditional state Medicaid programs, including the ability to offer financial incentives to providers for making improvements in service delivery; the capacity to collect, analyze, and use health service data to improve care; and the ability to use their

\footnotetext{
${ }^{1}$ S. Schoenbaum, "Creating the Framework for High Performing Health Care Organizations," presentation at a public hearing on health care provider and payer costs and cost trends, Boston, Mass., March 18, 2010.

${ }^{2}$ Kaiser Commission on Medicaid and the Uninsured, LowIncome Adults Under Age 65-Many Are Poor, Sick, and Uninsured (Washington, D.C.: Kaiser Family Foundation, June 2009).

${ }^{3}$ S. L. Decker, "In 2011 Nearly One-Third of Physicians Said They Would Not Accept New Medicaid Patients, But Rising Fees May Help," Health Affairs, Aug. 2012 31(8):1673-79.

${ }^{4}$ K. Gifford, V. K. Smith, D. Snipes et al., A Profile of Medicaid Managed Care Programs in 2010: Findings from a 50-State Survey (Washington, D.C.: Kaiser Family Foundation, Sept. 2011).
}

contractual relationships to attract and influence providers' behavior.

With a growing number of states choosing Medicaid managed care and the anticipated growth in the adult Medicaid population under the Affordable Care Act, it is an opportune time to investigate the extent to which managed care programs have fostered or could foster better care for Medicaid beneficiaries and strengthen the health care delivery system. For this study, we asked providers whether and, if so, how Medicaid MCOs have catalyzed delivery system improvement. The first section of the report describes activities in four communities to improve service delivery, including promoting service coordination, expanding access to providers, and fostering communication among providers. Providers report that although MCOs are involved in many such activities, they are not usually the primary sponsors. The next section discusses providers' perceptions of the challenges posed by managed care, including fragmented care delivery systems, limits on the types of services for which MCOs are at risk, and volatility in managed care markets.

\section{ABOUT THIS STUDY}

The four study communities are: Milwaukee, Wis.; Oakland, Calif.; Seattle, Wash.; and Washington, D.C. Each site has robust Medicaid or other state-funded coverage for a significant share of adults and uses a comprehensive risk-based managed-care approach. In addition, the selected communities are midsize cities with fairly diverse populations and strong safety-net institutions. The sites differ with regard to the types of managed-care plans operating, systems for covering behavioral health services, political circumstances, and geography (Exhibit 1 and Appendix 1).

The research team conducted interviews in early 2013 with providers and others familiar with local safety-net systems. Safety-net providers deliver a significant level of health care and health-related services to uninsured, Medicaid, and other vulnerable populations. Respondents included physicians and other primary care providers; administrators at hospitals, health clinics, 
EXHIBIT 1. CHARACTERISTICS OF STUDY COMMUNITIES

\begin{tabular}{|c|c|c|c|c|}
\hline Characteristic & Milwaukee & Oakland & Seattle & Washington \\
\hline Population (2012)* & 598,000 & 396,000 & 621,000 & 618,000 \\
\hline \% Nonwhite (2011): & $\begin{array}{c}\text { 44\% Black } \\
17 \% \text { Hispanic } \\
4 \% \text { Asian } \\
\end{array}$ & $\begin{array}{c}28 \% \text { Black } \\
25 \% \text { Hispanic } \\
17 \% \text { Asian } \\
\end{array}$ & $\begin{array}{c}\text { 8\% Black } \\
\text { 7\% Hispanic } \\
14 \% \text { Asian } \\
\end{array}$ & $\begin{array}{l}51 \% \text { Black } \\
9 \% \text { Hispanic } \\
5 \% \text { Asian } \\
\end{array}$ \\
\hline $\begin{array}{l}\text { \% Language other than } \\
\text { English at home*: }\end{array}$ & $19 \%$ & $40 \%$ & $22 \%$ & $15 \%$ \\
\hline $\begin{array}{l}\text { Medicaid income eligibility } \\
\text { for adults (\% FPL):* }\end{array}$ & Parents: $200 \%$ & Parents: $100 \%$ & Parents: $40 \%$ & $\begin{array}{c}\text { Parents and } \\
\text { childless adults: } \\
200 \% \\
\end{array}$ \\
\hline $\begin{array}{l}\text { Other state-funded coverage } \\
\text { for adults not eligible for } \\
\text { Medicaid (\% FPL) }\end{array}$ & $\begin{array}{l}\text { BadgerCare Core } \\
\text { Adults: } 200 \% \\
\text { (capped enrollment) }\end{array}$ & $\begin{array}{l}\text { HealthPAC, county } \\
\text { indigent care } \\
\text { program } \\
\text { Adults: } 200 \%\end{array}$ & $\begin{array}{c}\text { Basic Health } \\
\text { Program } \\
\text { Adults: } 200 \% \\
\text { (capped enrollment) }\end{array}$ & $\begin{array}{c}\text { DC Alliance } \\
\text { (state-funded) } \\
\text { Adults: } 200 \%\end{array}$ \\
\hline $\begin{array}{l}\text { Medicaid managed-care } \\
\text { market: }\end{array}$ & $\begin{array}{c}\text { Most enrollment in } \\
3 \text { commercial plans; } \\
\text { small enrollment in } \\
\text { other commercial } \\
\text { plans }\end{array}$ & $\begin{array}{l}\text { 2-plan model, with a } \\
\text { public-sector and a } \\
\text { commercial plan }\end{array}$ & $\begin{array}{l}5 \text { plans, including } \\
1 \text { community- } \\
\text { based plan and } 4 \\
\text { commercial plans }\end{array}$ & 3 commercial plans \\
\hline $\begin{array}{l}\text { Recent changes in Medicaid } \\
\text { managed-care market: }\end{array}$ & $\begin{array}{l}\text { Largest plan } \\
\text { withdrew in } \\
\text { 2012; status of } \\
\text { replacement } \\
\text { unresolved. }\end{array}$ & No change & $\begin{array}{l}\text { New competition } \\
\text { for plan contracts } \\
\text { effective in } 2012.2 \text { of } \\
\text { the original } 5 \text { plans } \\
\text { are among a new } \\
\text { group of } 5\end{array}$ & $\begin{array}{l}\text { Entry of } 1 \text { new } \\
\text { plan in } 2011 . \text { Entry } \\
\text { of } 2 \text { new plans in } \\
2013 \text {, to replace } 1 \\
\text { plan that went into } \\
\text { receivership and } 1 \\
\text { that was not chosen } \\
\text { in a new round of } \\
\text { bidding. }\end{array}$ \\
\hline $\begin{array}{l}\text { New populations for } \\
\text { Medicaid managed care }\end{array}$ & No change & $\begin{array}{c}\text { People with } \\
\text { disabilities shifted } \\
\text { to managed care in } \\
2011 \text { and } 2012\end{array}$ & $\begin{array}{c}\text { People with } \\
\text { disabilities shifted } \\
\text { to managed care in } \\
2012\end{array}$ & No change \\
\hline
\end{tabular}

Notes: FPL = federal poverty level. Adults with disabilities who receive Supplemental Security Income (SSI) benefits are also eligible for Medicaid.

* United States Census Bureau, State and County QuickFacts, http://quickfacts.census.gov/qfd/index.html.

** M. Heberlein, T. Brooks, J. Alker et al., Getting into Gear for 2014: Findings from a 50-State Survey of Eligibility, Enrollment, Renewal, and Cost-Sharing Policies in Medicaid and CHIP, 2012-2013 (Washington, D.C.: Kaiser Family Foundation, Jan. 2013), p. 33, http://kff.org/medicaid/report/getting-into-gear-for-2014-findings-from-a-50-state-survey-ofeligibility-enrollment-renewal-and-cost-sharing-policies-in-medicaid-and-chip-2012-2013/.

***: See Appendix 2 for more information on participating MCOs.

\section{EXHIBIT 2. INTERVIEW RESPONDENTS}

\begin{tabular}{l|c|c|c|c|c}
\hline Respondent type & Milwaukee & Oakland & Seattle & Washington & Total \\
\hline Program administrators & 2 & 19 & 9 & 5 & 35 \\
\hline Physician and other primary care providers & 10 & 13 & 4 & 6 & 33 \\
\hline Case managers/Care coordinators/Referral specialists & 3 & 13 & 2 & 13 & 31 \\
\hline Behavioral health providers and staff & 2 & 2 & 7 & 7 & 18 \\
\hline Others & 1 & 0 & 1 & 3 & 5 \\
\hline Total & 18 & 47 & 23 & 34 & 122 \\
\hline
\end{tabular}


and health plans; behavioral health providers; care coordinators; and county officials (Exhibit 2).

Most of the informants work directly with adult Medicaid beneficiaries and are familiar with health care services delivered to this population. A total of 122 individuals based in 40 organizations were interviewed across the four communities (Exhibit 3). Most interviews were conducted in person, using a semistructured discussion guide, and many interviews included a group of respondents (Appendix 3). Interviewees were assured that their responses would not be associated with individuals or institutions.

The nonrandom selection of communities and respondents limits the ability to generalize study findings to other communities, each of which has unique characteristics that influence its delivery systems. Similarly, each safety-net provider operates within a particular set of circumstances. Nevertheless, some findings and lessons may be broadly applicable across the nation. It is also important to note that providers' perceptions are the focus of this study. A similar effort to examine issues related to service delivery from a health plan perspective would provide a valuable complement to this work.

\section{ACTIVITIES TO IMPROVE SERVICE DELIVERY}

When asked to describe the types of activities needed to improve care in their communities, most respondents spoke about the need for better service coordination, including both care management for individual patients and broader collaboration among community stakeholders to ensure coordination.

\section{Care Management}

The term care management is used to describe a range of activities designed to foster communication among providers and help beneficiaries use health and social services effectively and efficiently. An intensive, individualized approach may include a mix of telephone calls and in-person meetings as well as reviews of medical records and consultations with providers. Care managers, also called case managers, frequently accompany patients to medical appointments and promote communication among providers and patients. They also may help clients obtain transportation, housing, or other social services. One case manager explained that she helps clients with benefit enrollment, recertification, or advocacy because "the materials that come to the home make no sense [to them] or change several times." Commonly, intensive care management occurs at health clinics, where caseloads range from about 30 to 150 patients. In situations involving patients with severe and persistent mental illness, caseloads may be even lower (e.g., 15 to 20 patients).

In one community, a new organization funded by a three-year federal grant provides intensive care management for managed-care enrollees identified by MCOs as high service users with certain chronic conditions. Health plans, local provider associations, health clinics, a safety-net hospital, and consultants support the project.

EXHIBIT 3. PARTICIPATING ORGANIZATIONS

\begin{tabular}{|c|c|c|c|c|c|}
\hline Locations & Milwaukee & Oakland & Seattle & Washington & Total \\
\hline Hospitals & 3 & 1 & 2 & 2 & 8 \\
\hline Health clinics & 4 & 2 & 3 & 4 & 13 \\
\hline Behavioral health clinics & 1 & 1 & 2 & 1 & 5 \\
\hline Managed care plans & $\mathrm{O}$ & 2 & 1 & $\mathrm{O}$ & 3 \\
\hline Nonprofit, advocacy, and trade organizations & $\mathrm{O}$ & 1 & 1 & 1 & 3 \\
\hline Care coordination or integration initiatives & $\mathrm{O}$ & 2 & $\mathrm{O}$ & 1 & 3 \\
\hline County public health departments & 1 & 3 & 1 & o & 5 \\
\hline Total & 9 & 12 & 10 & 9 & 40 \\
\hline
\end{tabular}


Providers report that in a few instances, MCOs conduct or fund intensive care management for patients. More commonly, providers reported that care managers employed by MCOs use an approach based on internal data reviews. They may flag enrollees who are frequent or expensive service users and either call them to encourage them to contact their primary care provider or send information directly to the provider. On the whole, providers observed that the care managers have little personal contact with enrollees. In describing care management activities, one clinic respondent said, "The thing is, you can't just do case management if you are an HMO who no one even knows. People know their doctor but not who is paying the bills. It's hard for them [the HMO care managers] to have an impact on people. If our case managers come out to patients' homes ... the patients are going to be feeding them.”

\section{Promoting More Appropriate Use of Emergency Departments}

Across communities, improvement activities most frequently focused on efforts to reduce unnecessary use of hospital emergency departments. Provider organizations most often initiated such activities, often supported by funding from private foundations, Medicaid waivers, or the Center for Medicare and Medicaid Innovation. Providers reported that MCOs do not appear to be major participants in these efforts.

For example, federal and state funds support the placement of a patient navigator in the emergengy department (ED) at one county hospital to help link patients to medical homes when they arrive for nonemergent care and to create a new clinic to which the most complex patients are referred. Another clinic uses grant funds to offer evening and weekend hours and hire a triage nurse for phone inquiries in order to provide an alternative to ED visits. One clinic provides care management services to help ensure that the psychosocial needs of patients with frequent ED visits are addressed. And one health plan participates in an experiment to electronically schedule follow-up primary care appointments for ED patients.
Facilitating Transitions from the Hospital to the Community

In the four communities, providers reported that most of the efforts to plan for posthospital services were initiated by providers. Hospitals' interest in these programs was spurred in part by public reporting of readmission rates starting in 2009 and the institution in 2013 of a Medicare payment penalty for hospitals with high readmission rates. For community clinics, the primary incentive to improve posthospital transitions was to find better ways to assist their patients. MCOs have incentives to improve posthospital care (i.e., to reduce the cost of readmissions), but providers reported that they generally did not initiate efforts to do so.

Respondents mentioned that some MCOs do send timely reports to primary care clinics when their patients are discharged from hospitals or work with hospitals on discharge management. One provider said that some MCOs had started providing information about hospital visits by their plan enrollees, but another commented that the communication was spotty and often incomplete, explaining that the MCOs "don't know what they don't know."

\section{Using Plan Data to Improve Service Delivery}

Some managed care plans attempt to engage primary care providers by sending them reports based on encounter data for their panel of patients. A few primary care providers were positive about these communications. One physician noted that it takes time to go through such reports but they "keep me on my toes." Another said that when he gets lists of patients who have not had physicals he asks his staff to try to schedule appointments.

More often, however, providers said that refinements are needed to improve the utility of the reports. Some called the lists they received "random events." They cited the need for more timely information available on a regular basis. Some were skeptical about the accuracy of the reports, noting that they are based on billing information, which does not always comport with information in patients' medical records. Others were concerned that they were being held responsible 
for patients who had been assigned to them by a plan, but who they had never seen. Providers suggested that there is a need to identify which types of data are most useful and to clarify how data can be used to inform efforts to improve health outcomes.

\section{Integrating Physical and Behavioral Health} Services

Providers in the four communities recognize the link between behavioral and physical health, but report that integrated physical and behavioral health care is difficult to achieve. One reason is that financial responsibility for behavioral health services for Medicaid beneficiaries is divided among organizations. In most of the communities, MCOs are at risk for only a limited set of behavioral health services such as outpatient treatment for mild or moderate mental health conditions. County health departments, which traditionally have administered and provided treatment for a continuum of mental health services including serious and persistent mental illness, continue to be responsible and reimbursed directly by Medicaid. Another complicating factor is that substance abuse and mental health services are frequently financially and clinically disconnected despite the fact that the two conditions often occur together.

This split between the entities at financial risk for physical health and those at risk for behavioral health services affects service delivery. One provider explained that although her clinic has the capacity to furnish coordinated physical and mental health services, she and her colleagues tend to refer their Medicaid patients to other providers because Medicaid pays the county, not the clinic, for mental health services. She noted, however, that when this occurs, patients do not have integrated care plans. Communication between the clinic and the county providers is minimal, and the system "prevents people from going to the best place to get the care they need."

Despite the barriers to integrating physical and behavioral health services, collaborative activities are occurring. One community initiative, funded by a grant from the state along with investment on the part of the local MCO that administers the program, provides training and professional support for mental health care coordinators embedded in care teams at community health clinics. Another community has a federal grant to provide onsite primary care at two behavioral health clinics. Separate federal, state, and local funds are used to hire more behavioral health providers, including psychiatrists, at health clinics that deliver primary care.

\section{Fostering Communication Among Providers}

The importance of good communication among providers in the Medicaid delivery system, especially between specialists and primary care providers, is broadly recognized as a key requirement for effective service delivery. But many providers indicated that this does not occur on a regular basis. Respondents expressed hope that electronic health records (EHRs) will eventually help. EHRs are used in most settings across the communities, and providers are generally positive about them. The biggest concern is the absence of interoperability among the EHR systems used by the various organizations that treat the same patients. Consequently, EHR systems are not viewed as major contributors to service coordination. Broader community efforts to promote the exchange of electronic health information typically are sponsored by state or local government entities or a provider coalition. There were few if any mentions of involvement by MCOs. What's more, managed care plans were not described as innovators in fostering communication.

\section{CHALLENGES ASSOCIATED WITH MANAGED CARE}

A common theme in discussions with providers and others was the view that certain elements of managed care may interfere with broader efforts to develop systems that deliver patient-centered care. Respondents reported that volatility in the managed care market is the most problematic factor because it disrupts care for beneficiaries and requires extra effort on the part of providers. In addition, respondents note that managed care is designed to improve quality by encouraging competition among MCOs, but this may limit the 
extent to which such plans participate in collaborative efforts.

\section{Volatility in the Managed Care Market}

Three of the four communities had experienced a major change in $\mathrm{MCO}$ offerings in the past year as the result of plan withdrawals or new bidding cycles. In each instance, beneficiaries losing a plan could choose among the new set of plans. If they did not choose a plan they were assigned to one and, in some cases, to a primary care provider. Providers report that assignments often occurred without taking beneficiaries' longstanding care relationships into account and without regard for their cultural or linguistic needs or preferences. In addition, mandatory transfers of new populations of Medicaid beneficiaries from fee-for-service to managed care systems occurred in two of the communities. In those instances, managed care as well as plan choice were new concepts to beneficiaries.

The prevailing sense among providers is that many beneficiaries are not aware of differences among plans, do not understand their choices, or are not in a position to think through the implications on an informed basis. They may not be aware of the type of coverage they have had or that a change has occurred. Several people explained that the population they work with moves frequently, does not always open or understand the mail they receive, and may not answer the telephone.

\section{Disruptions in the Delivery of Care Related to Volatility}

New plan assignments disrupt patient-provider relationships when established providers are not in new plans' networks. One clinic administrator called the situation "mayhem for our patients," explaining that beneficiaries would come to see their regular doctors only to learn the clinic did not participate in the network associated with their newly chosen or assigned plan. Plan assignment also interfered with one community's effort to encourage more appropriate use of the emergency department. Beneficiaries who arrived at the ED for nonemergent care were sent to the community-based clinic they identified as their source of primary care, only to be told when they arrived there that the clinic did not participate in their new assigned plan's network. The referral process also becomes more complicated when plan changes occur. Many clinics employ referral specialists to help arrange appointments for their patients. At one clinic, a referral specialist called plan networks "moving targets." Several referral specialists and physicians reported that they had fewer options for referrals when hospitals and specialists with which they had established relationships were not included in new networks. Most referral specialists did not mention using MCOs as resources.

Providers were particularly concerned about the need to intervene to ensure that previously authorized care continues when patients are enrolled in new MCOs. They cited examples of patients whose surgeries were delayed when a new MCO would not accept the prior plan's authorization.

\section{Diversion of Clinic Resources}

Some community-based clinics help patients who change plan affiliations so they can continue to be seen at their usual place of care. But the process is time-consuming and diverts resources from other clinic activities. In two settings that serve particularly vulnerable groups, clinic personnel described an onslaught of patients who brought in letters they received from Medicaid explaining changes in coverage, including the need to choose a managed care plan and asked for assistance because they did not understand what they were being asked to do or how to go about choosing plans.

Clinic administrators also spoke about uncertainty related to how they will be reimbursed when current managed care plans leave the market or new plans enter. Administrators must spend time negotiating contracts with new plans and learning plans' policies and procedures. Both health care providers and administrators mentioned that differences in policies and procedures among $\mathrm{MCOs}$ - including different provider networks, pharmacy formularies, referral authorization procedures, and certification requirements-complicate the practice of medicine and require additional 
administrative resources. Clinics often employ staff to assist with referrals, preauthorization, or other administrative issues related to managed care.

\section{Confusion Among Beneficiaries}

Providers perceived differences among MCOs in factors such as network capacity, availability of reliable transportation, types and amounts of supportive services offered, and plans' capacity to accommodate beneficiaries' needs related to language, literacy, culture, or disability. But for the most part providers did not think beneficiaries were aware of such differences among the plans. They observed that patients could be better consumers and make smarter choices about their use of health services if they were more familiar with the potential benefits of managed care as well as differences among managed care plans.

\section{POLICY RECOMMENDATIONS}

Observations from respondents across the four communities suggest that efforts on the part of managed care organizations to expand or enhance certain practices could promote more effective and efficient delivery of coordinated care. In addition, policy or operational changes on the part of states could promote patientcentered care and better population health management in Medicaid managed care programs.

\section{Recommendations for MCOs include:}

- More intensive care management and service coordination. MCOs could contract with local trusted providers or organizations, particularly those that are culturally competent and have experience in managing care for particular patient populations, including those with both physical and behavioral health needs. Plans also could develop their own care management programs, but respondents emphasized that programs relying on frequent inperson contact will be more effective than efforts to manage or coordinate care by telephone.

- More consistent and timely use of data. Primary care providers say that plans could encourage appropriate use of EDs or better transitions from hospital to home by providing encounter data about hospital visits to them on a timely basis. Further, hospitals suggested that opportunities for care coordination would increase if staff were able to contact MCOs to identify patients' primary care providers.

- Current information about provider networks.

Providers and referral specialists said that the task of making referrals to specialists would be easier if accurate and current network lists were readily available. They also noted that more assistance from plans would be helpful in facilitating referrals to specialists. For example, some suggested that MCOs operate hotlines to assist with referrals to specialists who have contracts with the plan.

- Reimbursement for innovative service delivery. To the extent that they are freed from some of the rules and policies associated with traditional Medicaid, MCOs could consider how to pay for services such as group visits or home visits, which safety-net providers cited as being particularly helpful for patients with complex conditions.

- Reimbursement for patient navigators and other nonphysician professionals and payment for supportive services, such as child care, transportation, or interpreters for medical appointments, could also help ensure that care will be patient-centered.

\section{Recommendations for changes in state policies and practices include:}

- Reduce volatility in the managed care market. Some degree of volatility in managed care markets is to be expected as states initiate new rounds of contract bidding or make changes to program requirements, and as the managed care marketplace evolves. But to minimize volatility, states could require that MCOs make long-term commitments to the program, discourage plan withdrawals by excluding reentry for a period of time, and minimize rounds of competition for new contracts. 
- Reduce adverse impacts of market changes. To

minimize disruption in care associated with market volatility, respondents suggested that states should consider beneficiaries' existing relationships with providers in making plan assignments. States also could include enhanced transition protections in $\mathrm{MCO}$ contracts. For example, states could require new plans to honor prior authorizations and provider relationships for ongoing care such as scheduled medical procedures and provide transitional supplies of off-formulary drugs.

- Broad initiatives to improve service delivery. There may be competing interests among managed care plans. To promote collaborative efforts, states could develop new performance measures or payfor-performance programs that credit MCOs for working with other community stakeholders to achieve positive changes in service delivery for Medicaid beneficiaries.

- Comparative information about plan choices. To encourage plans to compete on the basis of quality and to help enrollees and providers differentiate among plans, several people suggested that states could make comparative information about MCOs available to the public on a timely basis and in a form that is easy to understand.

\section{DISCUSSION}

Increasingly, state policymakers are turning to managed care to generate cost reductions in the Medicaid program, promote delivery system innovation, or both. This study did not examine cost savings, but found only limited evidence from providers' perspective that MCOs are catalysts for improvements in service delivery for Medicaid beneficiaries.
Despite differences in local circumstances and state Medicaid programs, common themes emerged in conversations with providers and others involved with safety-net delivery systems about the role of MCOs. According to providers, some MCOs are much more engaged in improvement efforts than others, but overall the plans are not seen as leading systematic or prolonged efforts to coordinate or otherwise improve care delivery. Fragmented health care delivery systems, especially the separate systems for physical and behavioral health services, create difficulties for both providers and plans. Furthermore, in states where MCOs compete for business within the Medicaid managed care systems, certain factors may make it more difficult to promote communitywide delivery system reform. In particular, limits on the types of services for which different MCOs are at risk, and the volatility in managed care markets, create challenges.

This research was designed to shed light on providers' views of how managed care affects the delivery of services for Medicaid beneficiaries. Thus, it does not present the assessments and opinions of all stakeholders. A study that examines issues related to service delivery for Medicaid beneficiaries from the perspective of health plans would complement these findings. Another limitation of the study is that it reports on activities in just four communities. Common themes occurred across the communities, but it is possible that outcomes from similar research conducted in other communities would produce other results, including more reports of improvement activity on the part of MCOs.

Activity and interest in Medicaid managed care are high and will likely increase with the planned expansion of Medicaid coverage for low-income adults in many states under the Affordable Care Act. Certain policy and operational changes, as well as ongoing program monitoring and evaluation, would promote patient-centered, coordinated care for beneficiaries. 


\section{APPENDIX 1. METHODOLOGY}

To accommodate the site visit format of the study, a single community was selected in each of four states.

The initial goal in selecting sites was to identify states that: 1) have robust adult Medicaid programs or other state-funded coverage, and 2) make substantial use of comprehensive risk-based managed care for this population. To select states from an initial list meeting these criteria, other factors were considered with goals of identifying variations on some criteria. The chosen communities offered a mix across several dimensions including geography; political circumstances; the type of managed care plans available (e.g., community-based and national health plans, public-sector and for-profit plans, Medicaid-only and broader plans); and approaches for covering and providing behavioral health services. Along some of the dimensions, such as the political circumstances, there are variations across communities. Along other dimensions, such as types of managed care plans, there are variations both across and within communities.

Although the findings cannot be generalized based on just four sites, patterns are easier to describe and discuss when some of the confounding factors are reduced. The consistent factors for the selected communities are:

- All are located in states that provide Medicaid coverage or other public coverage for parents and other adults without disabilities.

- All have well-established programs and a strong history of managed care.

- All are midsize urban areas.

- All have strong safety-net institutions.

- All have fairly diverse populations, in terms of race and ethnicity, as well as both documented and undocumented immigrant populations.

- All require plans to report on Healthcare Effectiveness Data and Information Set (HEDIS) measures.

- Information is readily available, as were good initial contacts, in each location.

In selecting potential respondents for the site visits, the goal was to interview providers and case managers who work with the adult Medicaid population, including those based in community health clinics, safety-net hospitals, behavioral health organizations, county health departments, and care management organizations. For the most part, interviews were not conducted with representatives of state Medicaid agencies or health plans. But a few health plan representatives, program administrators, and consumer advocates were consulted to provide details about health systems or particular initiatives.

Potential respondents were identified by identifying the larger safety-net provider organizations and other relevant organizations and then identifying contact persons in those organizations. The investigators for the project used their personal contacts, where available, and received assistance from colleagues in identifying other contacts. Through a snowball approach, the people contacted were asked for other contact names.

Most of the informants had regular contact with Medicaid patients. Group interviews were arranged in a number of organizations, enabling the participation of as many as 15 participants. These group interviews brought in a wider set of perspectives.

As shown in Exhibits 2 and 3, a total of 122 individuals based in 40 organizations were interviewed across the four communities. These involved 49 separate interview sessions. The exhibits also document the range of backgrounds of the respondents, including physicians, nurse practitioners, physician assistants, nurses, social workers, administrators, and other types of staff such as referral specialists. Nearly all interviews were conducted in person 
while on site, but for scheduling convenience a few were conducted by telephone before or after the site visit. Site visits were conducted in January through April 2013.

The semistructured interviews followed a general protocol (Appendix 3). The goal was to collect information consistently, while also pursuing the topics and concerns most relevant to the particular respondent. In addition, the approach allowed the interviewers the flexibility to follow up in more detail on specific topics relevant to the respondents or their organizations. The two senior investigators on the project conducted each interview. The research assistant took notes. Interviews were taped with the permission of the respondents, and the recordings were used later to supplement the notes. The protocol and all interview procedures were reviewed and approved by the Georgetown University Institutional Review Board, and the approved procedures were followed throughout the project.

After most interviews, the project team identified the key themes. This information was used both to highlight topics for emphasis in future interviews, as well as to start identifying themes for the project report.

\section{Managed Care Organizations}

The array of MCOs participating in Medicaid in three of the four communities changed before and after the site visits. Appendix 2 identifies MCOs that left the Medicaid program in the year prior to the site visits, those participating over a longer period, and those that had recently joined the program at the time of the site visits. 


\section{APPENDIX 2. MANAGED CARE ORGANIZATIONS IN THE FOUR COMMUNITIES}

\begin{tabular}{|c|c|c|c|c|}
\hline MCO Status & Milwaukee & Oakland & Seattle & Washington \\
\hline $\begin{array}{l}\text { MCOs that left } \\
\text { Medicaid in } 2012, \\
\text { prior to site visit }\end{array}$ & - United Healthcare & None & $\begin{array}{l}\text { - Columbia United } \\
\text { Providers } \\
\text { - Group Health } \\
\text { Cooperative }\end{array}$ & None \\
\hline $\begin{array}{l}\text { MCOs participating } \\
\text { with Medicaid since } \\
2010 \text { or earlier* }\end{array}$ & $\begin{array}{l}\text { - Children's } \\
\text { Community Health } \\
\text { Plan*** } \\
\text { - Community Connect } \\
\text { Health Plan } \\
\text { - Molina Health Care } \\
\text { - Independent Care } \\
\text { (iCare) }\end{array}$ & $\begin{array}{l}\text { - Alameda Alliance for } \\
\text { Health } \\
\text { - Anthem Blue Cross } \\
\text { Partnership }\end{array}$ & $\begin{array}{l}\text { - Community Health } \\
\text { Plan of Washington } \\
\text { - Molina Healthcare of } \\
\text { Washington }\end{array}$ & $\begin{array}{l}\text { - Chartered Health } \\
\text { Care* } \\
\text { - United Healthcare } \\
\text { Community Plan }\end{array}$ \\
\hline $\begin{array}{l}\text { MCOs new to } \\
\text { Medicaid as of } \\
\text { site visit }\end{array}$ & None & None & $\begin{array}{l}\text { - Amerigroup } \\
\text { - Coordinated Care } \\
\text { Corporation } \\
\text { - United Healthcare } \\
\text { Community Plan }\end{array}$ & - Medstar \\
\hline
\end{tabular}

* K. Gifford, V. Smith, D. Snipes et al., A Profile of Medicaid Managed Care Programs in 2010: Findings from a 50-State Survey (Washington, D.C.: Kaiser Commission on Medicaid and the Uninsured, Sept. 2011).

$* *$ Limited or no enrollment of adults.

$* * *$ Scheduled to exit the market soon after the time of the site visit. 


\section{APPENDIX 3. DISCUSSION GUIDE}

Purpose of this study: As we discussed, (or: as you know, from our email exchange), The Commonwealth Fund is sponsoring this research, which we are conducting to gain a better understanding of the extent to which state Medicaid programs have fostered positive changes in the health care delivery system, particularly for adults.

Statement of confidentiality: We can assure you that nothing that you say will be attributed specifically to you, or your organization. We are trying to get an overall sense of what's going on with adult Medicaid beneficiaries in your community by talking to several different organizations, and then we will synthesize everyone's comments in our final report. However, we do expect that we will identify individual communities because the programs and delivery systems in each location are so different. We will be visiting four communities.

Voluntary Participation: I want to acknowledge that your decision to talk with us is voluntary, and we really appreciate your time. If you need to stop at any time, that's fine. And of course, if there are any questions that you don't know the answer to, or don't want to answer, that's okay too. With your permission, we would like to record the interview. We will destroy the recordings at the conclusion of the project.

Any questions? Is it all right to proceed?

\section{Introduction}

1. Could you start by giving us a little background about your organization and your role there?

a. How long have you been there?

2. We want to talk today about care for Medicaid patients.

a. Have you seen major changes in health care for Medicaid patients in the last 5 years?

b. Has the use of managed care for Medicaid changed in the last 5 years?

\section{Care coordination}

1. How well are physical and behavioral health services coordinated?

a. Are depression screens done routinely? Who does them?

b. When problems are detected, how does the referral process work? Are "warm handoffs" on the same day to another provider in the practice or the clinic possible?

c. If behavioral health services are "carved out" of managed care plans, does that affect your ability to coordinate care or are there other ways to promote coordination?

2. We're particularly interested in hearing about any efforts to improve coordination when beneficiaries receive care from multiple providers. Are there particular policies or practices that facilitate coordination for Medicaid beneficiaries? (Please provide specific examples)

3. Do your patients work actively with case managers or care coordinators?

a. Who do they work for? How are they compensated?

b. Are peer counselors involved?

c. What functions do they perform?

d. Does care coordination benefit your patients? You? How? 
4. Are there situations when more than one case manager/coordinator/counselor is involved?

a. If so, how do providers or patients know whom to work with?

b. How is communication among coordinators and between coordinators and other providers achieved?

5. Are you part of an interdisciplinary care team? If so, please describe the advantages/disadvantages of the arrangement?

6. Are there any training programs or tools for providers that encourage better coordination?

a. If so, who sponsors them? Who conducts or provides them?

b. Is training regarding patients' cultural norms, preferences, or practices provided?

7. Are there policies, practices, or resources to help consumers with issues or services beyond the traditional medical model, such as food, housing, employment or job training, child care, availability of family and friends?

8. Are there particular protocols or extra services for "high need" individuals?

a. How are they identified? (medical conditions, nonmedical circumstances)

b. What do they receive? (home visits, "high-touch" follow-up, disease management)

c. Are services available through community services, clinics, hospitals, health plans?

d. Are there specialized health plans available for people with certain conditions or needs? Are they successful? Why or why not?

\section{Communication among institutions and providers}

1. Do providers generally communicate effectively with each other regarding care for your Medicaid patients?

a. If so, how does that occur? If not, what are the challenges?

2. To what extent do Medicaid managed-care plans or community hospitals or other providers help or hinder communication and the availability of information?

3. Are there policies and practices in place to promote communication between primary care providers and specialists?

4. Are there policies and practices in place to coordinate care for people who have been hospitalized or who use the $\underline{\mathrm{ED}}$ ?

a. How do you find out that your patient has been hospitalized or uses the ED?

b. Are you automatically informed about new medications that are prescribed in the hospital? What do you do with that information?

5. Do $\underline{\text { EHRs }}$ play a role in care coordination?

a. Is there a system for health information exchange?

b. Do providers have real-time access to medical records?

c. Who can communicate and view records electronically? Primary care providers, specialists, hospitals, case managers?

\section{Care in appropriate settings}

1. Are you aware of efforts to prevent rehospitalizations? Is the primary care doctor notified about follow-up care that is needed? What about referrals to specialists for follow-up? 
2. Are you aware of efforts to look at services that are provided in the hospital that could be better delivered in nonhospital settings?

3. Are you aware of policies/practices to decrease the use of EDs for nonemergency services?

a. Are primary care physicians or case managers notified of ED visits? Do they follow up?

\section{Access to care}

1. Do you place any limits on how many Medicaid patients you accept?

2. Has your policy on taking Medicaid always been the same?

3. Any difficulty in finding a doctor or other provider?

a. If there are access problems, what types of providers are most difficult to see?

b. Any issues getting other services: home health, imaging, etc., for your Medicaid patients?

c. Have you seen a change in access over the last 5 years?

4. Are you aware of accommodations to facilitate access for particular populations?

a. Transportation, physical accommodations, language, literacy, cultural competence.

b. If these services are needed, how are they arranged? Do you get involved?

5. Does the generosity (or limits) of the Medicaid benefit package have an impact on access?

\section{Preventive care}

1. Do the adult Medicaid patients in your practice get adequate attention for preventive care?

2. Particular policies, tools, training that help increase the delivery of preventive care services?

a. Is there a role played by the state Medicaid program in this regard?

b. Do Medicaid managed-care plans provide any particular resources or incentives?

c. Are there resources to help people with risk factors such as obesity, smoking, etc.?

d. Are you involved with disease management programs? Are they valuable?

e. Does anyone conduct comprehensive medication reviews for your patients?

f. Is there any particular effort to monitor adherence to medications?

\section{Managed care}

1. Overall, has managed care had a positive impact on service delivery for Medicaid patients?

2. Have changes in the market (plans leaving, new plans available) had an impact on the success of the some of the specific policies and practices we have discussed?

3. When people lose or regain Medicaid coverage or change plans, how is care affected?

4. Has managed care had an effect on payment rates for Medicaid patients?

a. Have rate changes affected the care they receive?

b. Are you aware of the increase in Medicaid payments for primary care? What effect?

\section{Wrap-up}

1. Is there anything we haven't asked about that you think might be useful for us to know? 
Throughout the discussion, follow up on particular policies and practices described by probing on the following:

a. Are there differences in the care delivered based on the status of low-income adult patients:

i. In Medicaid managed care versus fee-for-service systems

ii. In Medicaid today versus practices in earlier years

iii. In different Medicaid managed-care organizations serving the same population

iv. In Medicaid versus uninsured or with other types of insurance

v. As participants in special initiatives such as health homes

b. What are the incentives to provide services in this way?

i. Financial incentives? What type of payments or supports?

ii. State or plan reporting requirements?

c. Where did the policy/practice originate or who is responsible?

i. State Medicaid program

ii. Medicaid managed-care plan

iii. Provider organization

d. What are the challenges to developing or implementing specific practices?

i. How have challenges been addressed successfully? 
One East 75th Street

New York, NY 10021

Tel 212.606.3800
1150 17th Street NW

Suite 600

Washington, DC 20036

Tel 202.292.6700

www.commonwealthfund.org 